\title{
A feição nativista/indianista de Mário de Andrade ${ }^{1}$
}

Fábio Almeida de Carvalho ${ }^{2}$ Instituto Insikiran / Universidade Federal de Roraima

Resumo: $O$ artigo examina o modo por que Mário de Andrade dá continuidade - em diapasão gravemente dissonante - ao legado nativistaindianista do romantismo literário brasileiro.

Palavras-chave: Nativismo, Indianismo, Mário de Andrade.

Quase todo brasileiro medianamente letrado reconhece o fato de que Macunaina é protótipo de nossa brasilidade. Mas o que nem todos nós sabemos é que Macunaíma, a personagem de origem indígena e que assumiu por excelência a posição de "herói da nossa gente" brasileira, não é um herói genuinamente nacional. Aliás, foi o próprio Mário de Andrade, a despeito de ter seu "romancinho" imediatamente inserido na tradição nacionalista da nossa literatura, o primeiro a notar a presença de elementos que não são exatamente nacionais a marcar a (in)caracterização do nosso herói.

1. Uma muito pequena parte do texto que segue foi publicada no artigo intitulado "Mário de Andrade e a diversidade cultural brasileira", que compõe a coletânea de artigos que leva o título Diversidade cultural brasileira. Teresina: Não Ser, 2011.

2. Fábio Almeida de Carvalho é professor Adjunto do Instituto Insikiran de Formação Superior Indígena da Universidade Federal de Roraima. 
E de fato, Mário foi acusado, em mais de uma ocasião, pela contradição oriunda desse detalhe - tal o caso de Wilson Martins, que afirma que "o paradoxo está em que Mário de Andrade encontrou nas fontes internacionais a matéria brasileira de que necessitava, porque, aos seus olhos, a coletânea de Koch-Grünberg não era um livro alemão".

Eis caso clássico de uma única tacada crítica que intenta acertar dois alvos, pois, ao mesmo tempo em que o crítico literário relativiza a feição autoralnacionalista do projeto de Mário de Andrade - por ser ele tributário de "fontes internacionais" -, dá ênfase à suposição de que a obra assinada pelo etnógrafo alemão Koch-Grünberg nas páginas dos Mitos e lendas Taulipang e Arekuná não é, de fato, de sua autoria, em razão de que em última instância os autores seriam os seus informantes indígenas, Mayuluaípo, índio taulipang, e Akuli, arekuna. Não obstante, apesar de se fundamentar em dados da realidade, a objeção não parece ter pertinência, em razão de que Mário de Andrade não se apropriou, em sentido estrito, de lendário de origem alemã. O sentimento do escritor modernista era, aliás, o de que se apropriava de algo que, no mínimo, era também seu.

Mas fato é que os arquivos depositários do acervo de Mário de Andrade, mantidos pelo Instituto de Estudos Brasileiros da Universidade de São Paulo, comprovam que, no afamado escritório de trabalho localizado à Rua Lopes Chaves, 108, na Barra Funda, cidade de São Paulo, o escritor modernista possuía quatro dos cinco volumes de Vom Roraima zum Orinoco - somente o volume IV não foi encontrado em sua biblioteca. No "Prefácio escrito imediatamente depois de terminada a primeira versão" de Macunaíma, datado de 27-III-1928, Mário de Andrade declara que, quando matutava em descobrir o máximo que pudesse a "entidade nacional dos brasileiros", topou com Makunaima no alemão de KochGrünberg e, segundo confessa..., literalmente "gozou".

Conforme Telê Ancona Lopez, que dedicou todo um livro ao estudo da marginália produzida por Mário de Andrade no volume de Mythen und Legenden der Taulipang und Arekuna-Indianer, provavelmente "o ano da leitura e o primórdio da escritura de Macunaíma é fornecido de forma cifrada na Carta pras Icamiabas, capítulo IX: 'Trinta de Maio de Mil Novecentos e Vinte e Seis, em São

3. www.jornaldepoesia.jor.br/wilsonmartins029.html. Acessado em 22/01/12.

4. ANDRADE. Macunaíma; o herói sem nenhum caráter, 1978, 437 p. 
Paulo"'. 5 Esse momento marcaria a proto-história da gênese da obra, pois, conforme atesta a estudiosa do grande escritor, as "páginas de Vom Roraima zum Orinoco são para o leitor/autor [Mário de Andrade] como páginas de caderno próprio, onde os olhos se detêm sem cerimônia no que escreve, dando à mão liberdade de rasurar". ${ }^{6}$ As páginas desse exemplar constituem locus genesis privilegiado, porque guardam muitos vestígios do modo de apropriação e evidenciam o processo de transculturação daquele que, desde então, tornou-se, também de forma legítima, "herói da nossa gente".

E, ao encontrar Makunaima nas páginas de Vom Roraima zum Orinoco, Mário de Andrade gozou mesmo foi da sensação da grande descoberta, e teve a imediata iluminação eufórica dos que se deparam com novo e rico filão, haja vista que potencialmente capaz de prover de matéria-prima o projeto em que ele estava empenhado desde muito: moldar uma solução artística e literária para a construção de uma cultura própria para o Brasil. Entretanto, essa não foi tarefa de fácil realização, como pode até parecer à primeira vista, já que diz respeito a uma questão ligada a uma tradição discursiva bastante caudalosa em nossas letras, e que tem demandado o dispêndio de considerável energia ao longo da história do pensamento brasileiro. E é bem provável que, nessa tradição discursiva, talvez nenhum outro intelectual tupiniquim tenha se dedicado tão explícita e profundamente quanto Mário de Andrade à resolução desse verdadeiro nó górdio da nossa cultura.

A fim de fazer o exame do modo de apropriação da personagem no âmbito da cultura brasileira letrada, faz-se necessário apresentar en avant o pano de fundo sobre o qual foi decalcada a sua reinserção no solo da cultura literária brasileira. Em razão disso, examinaremos a seguir o tratamento dispensado pela cultura brasileira ao elemento indígena e, em seguida, a posição de Mário de Andrade no âmbito da nossa literatura, mediante a discussão do projeto intelectual levado a cabo pelo escritor modernista.

Antes disso, porém, faz-se necessário fixar que o movimento de afirmação das identidades dos povos americanos pode ser caracterizado por se estruturar em duas dimensões não obrigatoriamente excludentes ou

5. LOPEZ. O turista aprendiz na Amazônia: a invenção no texto e na imagem, p. 135-164.

6. LOPEZ. Revisitando Sísifo. Preparando a possessão. In: ANDRADE, Mário de. Macunaima, p. XXVII. 
complementares: a primeira centra-se na mobilização em torno de um vetor de ação cujas forças se concentram na intenção de marcar a especificidade da identidade cultural americana em relação à da metrópole, no período pós-colonial - tal o caso de Mário de Andrade, de que voltaremos a tratar na seção seguinte desse trabalho -; a segunda reúne forças em torno de um vetor direcionado para a face interna da questão, por meio do qual o totalitarismo homogeneizador dos estados nacionais passa a ser questionado pelas minorias dotadas de identidades historicamente apagadas ou subalternizadas enquanto parte do corpo social das nações - tal o caso da literatura de fatura étnica que ora desponta como fenômeno editorial no Brasil.

Tomando, pois, como ponto de partida, o panorama mais amplo da tradição literária brasileira, comecemos recorrendo a Antonio Candido que, em estudo sobre a Formação da literatura brasileira, afirma ser esta "eminentemente interessada", no sentido de que é "toda voltada, no intuito dos escritores e na opinião dos críticos, para a construção duma cultura válida no país. Quem escreve contribui e se inscreve num processo histórico de elaboração nacional”, e a consequência desse estado de coisas é que, diferentemente do que ocorre em outros países, a literatura se tornou o fenômeno central da vida e da pulsão do espírito no Brasil.

Operando com uma vertente de explicação tributária dessa corrente de pensamento, José L. Jobim afirma que, em diferentes momentos, a literatura brasileira tem desempenhado o papel de configurar, consolidar e disseminar uma noção de identidade nacional. Coube principalmente aos escritores ou littérateurs o papel de focalizar não apenas a realidade brasileira, mas também de elaborar um tipo de expressão que correspondesse à diferenciação cultural, linguística e literária de Portugal. ${ }^{8}$ É na qualidade, pois, de instrumento a serviço da definição identitária da nação que a literatura se manifesta como ato de brasilidade, a fim de exprimir a sensibilidade nacional.

Movimentando a esteira desse processo é que a figura indígena tem ocupado lugar de destaque desde o início da vida cultural letrada do país, haja vista que tem assumido dimensões de emblema de um programa coletivo organizado em favor da instituição do caráter nacional brasileiro. E prova irrefutável desse privilégio é o fato de que em mais de um momento o índio foi empregado

7. CANDIDO. Formação da literatura brasileira: momentos decisivos, p. 18.

8. JOBIM. Formas da teoria. 
como elemento principal para concretização da "cor local" e, nessa qualidade, é que tem sido alçado à condição de fator ativo e de longa duração no processo de elaboração de uma caracterização para a cultura brasileira. Tratando das causas desse fenômeno, José L. Jobim afirma que ora mais, ora menos a literatura tem conferido ao indígena "o papel de legítimo representante de uma origem nacional, anterior à presença do colonizador", "aquele que desde sempre aqui viveu, e lutou heroicamente contra os colonizadores estrangeiros".

A interpretação é plenamente válida quando consideramos que, desde o momento inicial de descoberta do Novo Mundo e da consequente construção do projeto de fixação do processo civilizatório, viajantes, pensadores e literatos europeus, bem como cientistas e escritores brasileiros, oriundos de diferentes campos de atividades e com orientações as mais diversas, se apropriaram da figura do indígena com o intuito de demarcar o que há de específico no locus cultural brasilicus. Com efeito, desde a "Carta", documento inaugural de nossas letras, em que Pero Vaz de Caminha, escrivão da esquadra de Cabral, informa a Dom Manuel, rei de Portugal, sobre o achamento da Nova Terra, a figura do indígena tem ocupado um lugar de destaque na cultura e, de modo particular, nas letras do Brasil. ${ }^{10}$

A apropriação da figura do índio se deu ora com conotação positiva (consubstanciada no mito da vida natural do bom selvagem), ora negativa (formulada na caracterização do bárbaro e em todo matiz de incivilidade, que vai do canibalismo ao desregramento sexual atribuído ao ameríndio). Disso resultou, conforme José L. Jobim, que a "figura do nativo foi preenchida com uma conceituação definida pelos termos contraditórios em que se estrutura”. ${ }^{11} \mathrm{E}$, nesse processo de construção da imagem do índio, dois principais tipos, viajantes e etnógrafos, de vária origem e monta, exerceram notória influência sobre a produção intelectual do Velho e do Novo Mundo. Ambos os grupos estabeleceram contato duradouro com os povos indígenas habitantes do Brasil desde o século XVI, e

9. JOBIM. Formas da teoria, p. 97-101.

10. Temos consciência de que a "Carta" conservou-se inédita durante séculos, tendo permanecido desaparecida até o ano de 1773, quando foi encontrada na Torre do Tombo, e que sua primeira publicação no Brasil data do início do século XIX. Não temos, pois, a intenção de propor uma leitura anacrônica para a "Carta", mas tão somente indicar que o índio constitui, desde aí, elemento central no gesto de definição do Brasil e dos brasileiros.

11. JOBIM. Formas da teoria, p. 50. 
reuniram o maior número e as mais consistentes informações sobre essas populações e seus hábitos. ${ }^{12}$

Apesar das diferenças, em decorrência das especificidades de cada caso, os produtores de cultura de aquém e de além-mar partilham o ponto de vista de que o indígena brasileiro constitui um elemento marcador da brasilidade em relação à matriz civilizacional europeia. Esse projeto ganhou concreção e também grande visibilidade e projeção por força da influência dos primeiros a explorar literariamente a temática indianista, casos de Basílio da Gama e Santa Rita Durão, mas teve seu mais alto grau de comprometimento durante a época romântica, mediante a valorização da obra de autores da cepa de um Gonçalves de Magalhães e de um Gonçalves Dias, dentre outros menos incensados pela história cultural do nosso país. ${ }^{13}$

Nesse cenário, posição de destaque foi assumida pelo coevo Joaquim Norberto que, empregando chave de interpretação teórica, defendia a posição ultrarradical de que, em razão da propensão natural do índio brasileiro para as artes, a poesia e a literatura, devia existir, por conseguinte, uma literatura autenticamente indígena, à qual deveria caber o mais importante papel na formação da nascente nacionalidade brasileira. ${ }^{14}$ Mas o momento mais agudo dessa verdadeira "solução de compromisso" da inteligência nacional ocorreu por intermédio do projeto literário idealizado e levado a cabo por José M. de Alencar, cuja obra foi em parte construída explicitamente com o empenho de tratar de maneira épica aspectos da natureza americana e de seu nativo.

Antonio Candido demonstra que os escritores neoclássicos já escreviam animados pelo desejo de construir uma "literatura empenhada", mas que depois da independência o pendor muito se acentuou, levando a considerar a atividade literária como "parte do esforço de construção de um país livre"." Para

12. Para aprofundamento das questões referentes a essas duas vertentes contrastantes da caracterização do elemento indígena e seu aproveitamento nas manifestações culturais do pensamento europeu e americano são valiosos os estudos de Afonso Arinos de Melo e Franco sobre $O$ indio brasileiro e a revolução francesa (1976), e de Ronald Raminelli, sobre as Imagens da colonização. A representação do índio de Vieira a Caminha (1996).

13. CANDIDO. O Romantismo no Brasil. 104 p.

14. SILVA. História da literatura brasileira e outros ensaios, 424 p.

15. CANDIDO. Formação da literatura brasileira: momentos decisivos, p. 26. 
tanto, bastante contribuiu a publicação, em 1826, do Résumé de l'histoire littéraire du Portugal suivi du résumé de l'bistoire littéraire du Brésil, do historiador francês Ferdinand Denis. Em razão de ter vindo à luz logo depois da independência do Estado brasileiro e da influência de longo prazo que exerceu sobre a nossa inteligência nascente e em vias de construção, a obra de Denis pode ser considerada fundadora da teoria e da história da literatura brasileiras. $\mathrm{O}$ autor francês defendia, conforme Antonio Candido, que "um país com fisionomia geográfica, étnica, social e histórica definida deveria necessariamente ter a sua literatura peculiar, porque esta se relaciona com a natureza e a sociedade de cada lugar [e deveria] portanto se concentrar na sua natureza e costumes". ${ }^{16}$

Mediante essa forma de moldar a realidade é que o habitante primitivo assumiu, em certos momentos da história cultural brasileira, o status de mais autêntico símbolo de brasilidade, e se apresentou como o caminho mais favorável à expressão da nação recém-fundada, pois que capaz de fornecer modelos que permitem afirmar o particularismo, ou seja, a "identidade local”, em oposição à da Metrópole, identificada com a tradição clássica. E foi por esse viés que foi sendo criado um lugar de inscrição e de interpretação da história e da cultura nacional, e que se foi consubstanciando uma concepção de nação em que a figura do indígena emergiu como um emblema capaz de abarcar e de esgotar as dimensões individuais e coletivas da identidade local.

Esse modo de conceber a noção de identidade nacional foi formulado de maneira recorrente no pensamento e na literatura brasileira, a ponto de exibir um lastro que em muito ultrapassou o campo do imaginário cultural do Romantismo literário, haja vista que exerceu uma complexa e duradoura influência, que se expandiu para muito além dessa época. Assim é que, do mesmo modo que aconteceu com os escritores do período romântico, a força motriz desse esquema mental foi capaz de insuflar a vida e a atitude dos escritores do período modernista, que também se impuseram o compromisso social de definir, construir e inventar uma genuinidade para a identidade cultural brasileira. No balanço do Modernismo, feito em conferência realizada no ano de 1942, Mário de Andrade exprime a questão nos seguintes termos: "Esta necessidade espiritual, que ultrapassa a literatura estética, é que diferença fundamentalmente Romantismo e Modernismo, das outras escolas de arte brasileiras". ${ }^{17}$

16. CANDIDO. O Romantismo no Brasil, p. 21.

17. ANDRADE. Aspectos da literatura brasileira, p. 250. 
É abordando o problema a partir da perspectiva que estabelece linha de continuidade entre os dois momentos ou períodos literários que M. Cavalcanti Proença propõe o tracejar de uma corrente programática que une José de Alencar a Mário de Andrade, e Iracema a Macunaíma. E realmente temos de concordar que, sendo determinado por alcunha ritmada em forma de perfeita redondilha maior - "o herói sem nenhum caráter" -, desde o título a obra de Mário de Andrade parece fazer alusão à "virgem dos lábios de mel". Para Cavalcanti Proença, ambos são exemplos de romances fundadores da identidade nacional não somente porque partem de um projeto claramente nacionalista, mas também porque tematizam o desajustamento entre a mentalidade primitiva e a civilizada e, senão também, porque têm pretensão de manifesto linguístico ou plataforma de construção de uma língua nacional. ${ }^{18}$

Para fins de dar sustentação à argumentação e corroborar a coerência dessa linha de continuidade proposta por M. Cavalcanti Proença, podemos invocar não apenas a primeiríssima notícia de Mário de Andrade sobre sua revolucionária obra, anunciada em carta escrita a Carlos Drummond de Andrade, em 18 ou 19 de janeiro de 1927, na qual informa, de maneira um tanto consciente, que Macunaíma trata de um "índio legítimo que me filiou aos indianistas de nossa literatura e andou fazendo o diabo por esses Brasis à procura dua muiraquitã perdida"; ${ }^{19}$ mas, sobretudo, a dedicatória que consta nos manuscritos da "versão definitiva" de Macunaima: "A Paulo Prado/José de Alencar pai de vivo que brilha no vasto campo do céu".

A curiosa expressão acima sublinhada tem valor apositivo e inconteste origem indígena. Ela institui as estrelas como entidades-guias e protetoras dos seres que vivem na terra. E nesse sentido, atesta que, à hora da criação de Macunaíma, José de Alencar assumia para o escritor modernista a condição de principal representante do programa de nacionalização da cultura brasileira, no qual ele conscientemente também se inseria. E assim sendo, a expressão sublinhada se institui de verdadeiro valor de vestígio da existência daquela espécie de fio

18. PROENÇA. Roteiro de Macunaíma, p. 34. Nessa obra, o autor faz breve, mas interessante, abordagem de alguns pontos de contato entre Iracema e Macunaima, e atesta que, diferentemente de J. de Alencar, cujas fontes são os cronistas, as fontes principais de M. de Andrade são os etnógrafos.

19. ANDRADE. Macunaima, p. 490.

20. ANDRADE. Macunaíma. Edição crítica, 1997, p. 447. 
condutor à moda de cordão de Ariadne, que mantém a ligação entre os dois escritores - sorte de certeza da direção a ser seguida, com avanços, recuos, e muitos desvios, no percurso do verdadeiro labirinto que é a definição de um caráter próprio para a cultura do Brasil.

Em contraponto a esse veio argumentativo, buscando fornecer explicação para o fato de Mário de Andrade não ter publicado a parte do texto que homenageia José de Alencar, tendo restado apenas o nome de Paulo Prado na dedicatória, Telê Ancona Lopez aventa, de forma um tanto plausível, embora francamente especulativa, a hipótese de que a "retirada da dedicatória quis talvez evitar que, na homenagem ao mestre do Romantismo, tomassem Macunaíma como uma obra 'indianista' " [...] e [acrescenta: para] "não suscitar polêmica em torno de Alencar, então criticado pela Antropofagia, mostrando publicamente divergências dentro do grupo modernista". Ao aceitarmos como válida a explicação de Telê Ancona Lopez, esse pormenor parece assumir importância significativa para a validação da interpretação que traça a linha de continuidade que ora vimos apresentando, haja vista que a aproximação é dialetizada por um franco distanciamento lateral, que também assume caráter programático.

Assim, ainda que não se possa negar que, em certa medida, Macunaíma dá continuidade e aprofunda diversos aspectos do projeto de Iracema, não podemos deixar de esboçar uma linha de franca dissensão entre as duas obras. Dessa perspectiva, em que se percebe a questão a partir de ângulo invertido, temos de contrapor o fato de que o Modernismo é concebido, por muitos estudiosos da questão, como o momento inaugural em que a problemática do nacional é colocada em termos de uma visão crítica sobre a realidade brasileira. Tal é o caso de Alfredo Bosi, que chama a atenção para os problemas decorrentes da tentativa de estabelecer paralelos entre Iracema e Macunaima, e defende que a obra modernista representa aberta ruptura, sobretudo no que diz respeito ao modo "extremamente livre de assumir a linguagem oral da escrita". Para A. Bosi, Mário de Andrade não tinha a pretensão de compor uma obra em língua brasileira, preocupação que se colocava, todavia, no horizonte de expectativas de José M. de Alencar. ${ }^{22}$

21. LOPEZ. Introdução. In: ANDRADE. Macunaíma, 1978, p. XVI-XIX (Nota 4).

22. BOSI. Dialética da colonização, p. 175. 
Entretanto, mais importante que isso, no momento, é fixar o fato de que Macunaíma já não carrega na dimensão de sua brasilidade aqueles "todos bons sentimentos portugueses" - como notou, tão aguda e jocosamente, Oswald de Andrade -, que são característicos das personagens indígenas de José de Alencar e de seus contemporâneos, especialistas na arte de isolar o índio de sua cultura. ${ }^{23}$ Diante disso, importante se torna notar, ainda na esteira de Telê Ancona Lopez, que o "passo à frente" nessa chave de interpretação da nacionalidade foi dado por meio da compreensão da condição sociológica do brasileiro e do índio, mediante a caracterização da situação histórico-econômica vivenciada pelas diferentes "raças" que compõem o povo brasileiro. ${ }^{24}$

Frente ao que acima foi dito, uma explicação parece necessária: não obstante reconhecermos a validade das ressalvas feitas por Alfredo Bosi à interpretação de M. Cavalcanti Proença, os aspectos definidores da filiação acima apresentados têm, para nós, a vantagem de indicar uma situação de continuidade que achamos interessante ser tracejada, ainda que em traços grosseiros, para demonstrar o modo pelo qual Mário de Andrade se insere, de forma muito particular, de maneira fortemente dissonante, para usar de uma metáfora musical, na tradição indianista da nossa literatura, sobre a qual agiu com o duplo intento de, por um lado, dar continuidade e aprofundar, e por outro, de romper e mesmo dilacerar os veios abertos pela produção do escritor romântico.

Ademais, temos de fixar que o Modernismo brasileiro se caracteriza não apenas como um movimento de ruptura com o passado, haja vista que se articula a partir da necessidade de pensar e construir uma atualização estética para o Brasil, em consonância com as contradições inerentes a uma cultura colonizada, mas em vias de modernização e de emancipação. Diferentemente do Romantismo, o Modernismo inaugura um novo momento da dialética do universal e do particular, agora fundada na diversidade cultural, uma vez que o contato com as vanguardas europeias despertou a consciência de que um novo tratamento estético e ideológico deveria ser conferido às raízes africanas e indígenas. Na lógica desse novo paradigma, se não havia espaço para o heroísmo de pendor idealizante da personagem indígena, que antes havia sido transfigurada em cavaleiro medieval das Américas, também

23. ANDRADE. Do Pau-Brasil à antropofagia e às utopias, p. 11-19.

24. LOPEZ. Macunaima: a margem e o texto, p. 75-83. 
não havia espaço para a reificação daquilo que Alfredo Bosi designa como o "complexo sacrificial' do indígena, tão presente e constante na mitologia de Alencar".

Para Antonio Candido, o Modernismo constitui o momento literário em que "[...] o mulato e o negro são definitivamente incorporados como temas de estudo, inspiração, exemplo. O primitivismo é agora fonte de beleza e não mais empecilho à elaboração da cultura". Pouco adiante, o autor acrescenta que, em Macunaíma, Mário de Andrade compendiou “[...] lendas de índios, ditados populares, obscenidades, estereótipos desenvolvidos na sátira popular, atitudes em face ao europeu, mostrando como a cada valor aceito na tradição acadêmica e oficial correspondia, na tradição popular, um valor recalcado que precisava adquirir estado de literatura". ${ }^{26}$

Ocorreu que, passada a euforia da "fase heroica" do movimento modernista, considerada malograda na sua tentativa de quase simples incorporação dos novos códigos literários absorvidos das vanguardas de importação, já em 1924 se pode acusar o aprofundamento da busca das tradições como mediadoras do nacional, ou melhor, do brasileirismo, como atestam as palavras de Mário de Andrade, em carta na qual oferece uma lição ao poeta e amigo Carlos Drummond de Andrade:

O nosso contingente tem de ser brasileiro. O dia em que formos inteiramente brasileiros e só brasileiros a humanidade estará rica de mais uma raça, rica da combinação de qualidades humanas. [...]. Os tupis em suas tabas eram mais civilizados que nós nas nossas casas de Belo Horizonte e São Paulo. Por uma simples razão: não há civilização. Há civilizações... Nós só seremos civilizados em relação às civilizações no dia em que criarmos o ideal, a orientação brasileira. Então passaremos da fase do mimetismo, pra fase da criação. E então seremos universais, porque nacionais.

Disso basta reter que, apesar da dissensão acima delineada entre românticos e modernistas, não se pode negar que os escritores do período modernista, sobretudo Mário de Andrade, deram continuidade, ainda que em

25. BOSI. Dialética da colonização, p. 179.

26. CANDIDO. Literatura e sociedade, p. 127-128.

27. ANDRADE. A lição do amigo: cartas de Mário de Andrade a Carlos Drummond de Andrade, p. 14-16. 
diapasão dissonante, à construção do projeto literário de caráter nacionalista do período romântico.

A corroborar esse dado há o fato de que, em 1928, quando foi dada à luz a primeira edição de Macunaíma, a recepção da época foi marcada por um viés nacionalista e pela proliferação de associações do herói a um suposto caráter nacional brasileiro, que transparece nitidamente na crítica de Tristão de Athayde/ Alceu de Amoroso Lima, publicada em OJornal, em 9/9/1928:

O Sr. Mário de Andrade é o homem menos romântico que possa haver. Nunca escreve por paixão. Por prazer sim. Mas, sobretudo, por procura, por pesquisa para encontrar o Brasil. O Brasil-alma e o Brasil-corpo, mas não o Brasil país. Penso que lhe falta singularmente o sentido de nacionalismo político. Mas tem agudamente o senso do nacionalismo orgânico e social, da busca ao caráter que nos distinga na América e nos marque pra sempre. Daí a sua irritação contra a nossa falta de personalidade e a consagração dessa ausência em distintivo, por meio de uma figura como Macunaíma. Pois queira ou não queira o "consciente" do autor, o que o seu sub-consciente nos deu, em Macunaíma, foi, em grande parte o "homo-brasilicus" em toda a sua deficiência, embora sem os sinais de tese sistemática e antes uma enorme liberdade de composição. $^{28}$

Tristão de Athayde não esteve só no que diz respeito ao emprego dessa chave de interpretação de Macunaíma pelo nacional. Nesse mesmo ano, Antônio de Alcântara Machado afirma, nas páginas da Revista de Antropofagia, que Macunaíma veio "pôr no seu devido pé a famigerada brasilidade atrás da qual correm suados e errados desde muitos anos os escritores deste Brasil tão imenso mas tão arraial ainda." Pouco adiante, o autor de Cavaquinho e saxofone acrescenta: "Mário é um pedacinho do herói. O herói somos nós todos juntos. Até eu, porque não?" sua própria crítica, quis-nos pintar o homem brasileiro [...]"; ${ }^{30}$ no ano seguinte,

28. ATHAYDE. Macunaíma. In: ANDRADE. Macunaíma; o herói sem nenhum caráter, p. 338-339.

29. MACHADO. Mário de Andrade: Macunaíma. In: ANDRADE. Macunaima; o herói sem nenhum caráter, p. 340-341.

30. RiBeiro. Macunaíma, Herói sem nenhum caráter - por Mário de Andrade. In: ANDRADE. Macunaíma; o herói sem nenhum caráter, p. 344-346. 
Augusto Meyer diz que Macunaíma "[...] parece retratar a psicologia média do brasileiro [...], embora ganhe proporções de símbolo"; ${ }^{31}$ nesse mesmo ano, o poeta Jorge de Lima assevera que "A tinta vermelha do tinteiro do subconsciente de Mário deu um borrão parecido com o Brasil: Macunaima"; ${ }^{32}$ Ronald de Carvalho afirma que "Mário de Andrade projetou o Brasil nessa figura".

Mesmo os que criticam a suposta representação nacional, caso de Nestor Vítor, acreditam que o livro pertence a um movimento nacionalista:

Seja como for, o que se torna patente na leitura de Macunaíma é isso: é que o Dadaísmo europeu, passando para o Brasil e produzindo aqui um movimento literário dionisíaco de arremedo, vai, contudo, estimulando os nossos moços para tentarem uma literatura nacionalista que entre em simbiose com as particulares disposições nesse rumo que a guerra em toda parte suscitou. ${ }^{34}$

Dissonâncias à parte, o certo é que não podemos negar que, talvez mais que qualquer outra obra da nossa tradição literária, Macunaima opera em contraponto com a tradição romântica de idealização do caráter nacional, ou seja, em atitude de franca ruptura com o ethos concebido como típico do brasileiro no período romântico. Dessa perspectiva podemos, em suma, conceber Macunaíma como a realização mais anti-Iracema da nossa literatura e, em função dessa constatação, inserir a obra de Mário de Andrade em determinada tradição nacional da literatura de veia cômica ou satírica, cujo fio começou a ser distendido ainda na época romântica, com as Memórias de um sargento de milícias, de Manuel Antônio de Almeida, e que se desenvolveu, passando pelas Memórias póstumas de Brás Cubas, de Machado de Assis, no período realista, até desaguar, no período modernista, em obras como Memórias sentimentais de João Miramar e Serafim Ponte Grande, ambas do confrade modernista de Mário, Oswald de Andrade.

31. MEYER. Macunaíma, por Mário de Andrade. In: ANDRADE. Macunaíma; o herói sem nenhum caráter, p. 347-348.

32. LIMA. Macunaíma: um raide no subconsciente nacional. In: ANDRADE. Macunaíma; o herói sem nenhum caráter, p. 348-351.

33. Carvalho. Macunaíma, de Mário de Andrade. In: ANDrade. Macunaíma; o herói sem nenhum caráter, p. 352.

34. VICTOR. Macunaíma. In: ANDRADE. Macunaima; o herói sem nenhum caráter, p. 341-344. 
Macunaíma se filia, com certeza, é a essa tradição amoralista e irreverente da tradição literária nacional, ligada às raízes folclóricas e populares da cultura brasileira. E é por essa via que a rapsódia modernista se inscreve no veio do nacionalismo crítico. ${ }^{35}$

Ao assumirmos a explicação de Antonio Candido, não podemos esquecer que a década de 1920 é um momento eivado de tendências que se opõem em suas concepções fundamentais quanto à definição ideológica da inteligência brasileira. Telê Ancona Lopez informa sobre a existência de pelo menos três tipos ou modalidades distintas de modernismos: a primeira, na qual podem ser enquadrados Mário e Oswald de Andrade, se interessa "pela experiência soviética, pela aplicação do Marxismo e a reivindicação do nacionalismo como primeiro passo para o internacionalismo"; enquanto a segunda, à qual se filiavam Plínio Salgado e Cassiano Ricardo, dentre outros articuladores das correntes da Anta e do Verde-amarelismo, negava o Marxismo e a tentativa de valorização de uma internacionalidade futura, ao tempo em que assumia de forma integral e aplaudia as concepções estéticas e políticas do futurismo italiano. Essa vertente, que tendeu para a atuação política de extrema direita, mantinha forte oposição a Pau-Brasil e à Antropofagia. Finalmente, a corrente da intelectualidade católica, organizada por meio do grupo de Festa, e composta por intelectuais como Tristão de Athayde e Jackson de Figueiredo, mais envolvida com a preocupação com os destinos espirituais do homem.

Realizado o delineamento dos contornos mais gerais da posição de Mário de Andrade na tradição literária brasileira e no Modernismo tupiniquim, a fim de que possamos melhor entender o lugar e a função de Macunaíma no projeto estético-histórico-ideológico do escritor, faz-se necessário traçar o percurso de formação intelectual do autor e o modo pelo qual ele foi transformando o seu aprendizado em obras que marcariam de maneira profunda a inteligência e a literatura brasileiras do século XX. E para tanto, temos de partir do reconhecimento de que a atuação intelectual e literária tinha, para Mário de Andrade, o peso de uma legítima profissão de fé, em razão que ele sofria de um verdadeiro "desespero ético”, que acabou, como tão bem definiu Guilherme Figueiredo, por conduzi-lo a

35. A tese do desacordo do processo de redução estrutural da realidade para a obra literária encontra-se desenvolvida no ensaio "Dialética da malandragem", de Antonio Candido, e, em perspectiva diversa, em dois estudos de Roberto Schwarz sobre a obra de Machado de Assis: Ao vencedor as batatas (1992) e Um mestre na periferia do capitalismo (1991).

36. LOPEZ. Ramais e caminhos, p. 196. 
Comprometer-se consigo mesmo. [... Por isso] Escolheu a solidão. Por amor à vida. A uma outra vida, impossível, inalcançável. Em que as mulheres seriam filhas namoradas. E com os homens o inconfessado desejo pecaminoso de torná-los irmãos. [...] Sem traições políticas, estéticas. Sem fingimento de "moderno": a repugnância de uma hipocrisia estética. [Empenhou-se pela] Nacionalização do idioma. A nacionalização do pensamento. A procura de uma brasilidade que recria o Brasil e o mundo, não como se fôssemos uma rara espécie da humanidade, mas como uma original contribuição cultural para a formação do entendimento humano. O desejo e o dever de participar da justiça. Não impô-la: oferecêla como um dado essencial à humanização do homem.

O depoimento atesta o compromisso do autor com a formação de uma consciência crítica em termos coletivos; com uma militância capaz de alterar a percepção e a atitude da geração da qual fez parte em relação ao entendimento da vida intelectual brasileira e de seus rumos ainda tão vacilantes, como diagnostica tão bem A. de Alcântara Machado. ${ }^{38}$

37. FIGUEIREDO. In: ANDRADE. A lição do guru. Cartas a Guilherme Figueiredo - 1937-1945, p. 22-23.

38. Se o problema parece de menor importância nos dias de hoje, em que o Brasil supostamente goza de prestígio e de reconhecimento internacional, bem diferente era a situação nas décadas de 1920 e 1930. Prova disso é o testemunho de Ronald de Carvalho (1931, p. 111), que afirmava na abertura de sua breve história militar do Brasil: "somos um povo muito mal julgado. A Europa nos desconhece, confunde as nossas origens ethnicas e históricas com as dos nossos vizinhos espanhóis, sabe apenas que habitamos um território imenso, rico de metais e pedrarias, abundante em matéria prima de toda espécie. Gustave Le Bon declarou que éramos uma nação hispano-americana, igual à Argentina, ao Peru ao Chile. Lapouge afirmou, no Aryano, que o 'Brasil era um grande estado negro que regressava à barbária'. O barão de Gobineau escreveu que éramos uma sub-raça, sem importância histórica, indigna de merecer atenção de sociólogos avisados. Paul Adam humilhou-nos com os seus hiperbólicos louvores, comparando as nossas poetisas campanudas aos maiores escritores da academia francesa. Blasco Ibañez só enxergou no Rio de Janeiro uma colmeia, de negroides seminus, regando as sargetas das ruas ao sol caldante dos trópicos abrasadores, com as secreções da bexiga. Jules Hurst, por mal da fatalidade, desembarcou, aqui, numa noite de carnaval... O que lhe interessou em nossa capital foram as orquídeas da Tijuca e os micos do Silvestre. De um viajante francês, recebemos a carinhosa epígrafe conhecida: no Brasil, os frutos não têm sabor, os homens não têm vergonha e as mulheres não têm pudor". 
Diferentemente de escritores como Guilherme de Almeida e de Ronald de Carvalho, empenhados antes em exprimir a realidade brasileira, Mário de Andrade estava comprometido em conhecer para representar e exprimir o Brasil mediante a investigação e a pesquisa profundas. Foi por assumir essa concepção que Mário de Andrade pôde aderir, segundo Antonio Candido, ao estudo dos "elementos recalcados da nossa civilização, como o negro, o mestiço, o filho de imigrantes, o gosto vistoso do povo, a ingenuidade, a malandrice, [elaborando] as diversas tendências do movimento numa síntese superior". ${ }^{39}$ E se, com efeito, o autor de Pauliceia desvairada pode ser apontado, dentre todos os intelectuais de sua geração, como o mais empenhado na afirmação da entidade nacional brasileira, Macunaíma é a melhor expressão desse empenho.

\title{
The nativist/Indianist aspect of Mário de Andrade
}

\author{
Abstract: This article examines the manner in which Mário de Andrade \\ continues - in severely dissonant diapason - the nativist-Indianist legacy of \\ Brazilian literary Romanticism.
}

Keywords: Nativism, Indianism, Mário de Andrade.

$$
\text { Referências }
$$

ANDRADE, Mário de. Macunaíma: o herói sem nenhum caráter. Edição crítica de Telê Porto Ancona Lopez. Rio de Janeiro: Livros Técnicos e Científicos, 1978.

ANDRADE, Mário de. O turista aprendiz. São Paulo: Duas Cidades, 1983b.

ANDRADE, Mário de. Aspectos da música brasileira. Belo Horizonte; Rio de Janeiro: Villa Rica, 1991.

ANDRADE, Mário de. Macunaíma. Ed. crítica de Telê Ancona Porto Lopez. Madrid: ALLCA XX, 1997.

ANDRADE, Mário de. Macunaíma, o herói sem nenhum caráter. Rio de Janeiro: Agir, 2008.

ATHAYDE, Tristão de. Mário de Andrade: Macunaíma. In: ANDRADE, Mário de. Macunaíma: o herói sem nenhum caráter. Ed. crítica de Telê Porto Ancona Lopez. Rio de Janeiro: Livros Técnicos e Científicos, 1978.

39. CANDIDO. Literatura e sociedade, p. 130. 
CANDIDO, Antonio. Formação da literatura brasileira: momentos decisivos. 6. ed. Belo Horizonte: Itatiaia, 1981.

CANDIDO, Antonio. O Romantismo no Brasil. São Paulo: Humanitas, 2002.

CANDIDO, Antonio. Literatura e sociedade. Rio de Janeiro: Ouro sobre Azul, 2008.

CARVAlHO, Fábio Almeida de; JOBIM, José Luís. Caminhos de um herói transnacional. In: SOUZA, Roberto Acízelo; HOLANDA, Sílvio Augusto de Oliveira; AUGUSTI, Valéria. (Org.). Narrativa e recepção: séculos XIX e XX. Rio de Janeiro / Niterói: De Letras/EDUFF, 2009.

CARVAlHO, Fábio Almeida de. Mário de Andrade e a diversidade brasileira. In: ALBUQUERQUE, Marleide Lins de. Identidades e diversidade cultural. Teresina: Edições Avant-Garde / FUNDAC, 2011.

CARVAlHO, Ronald. Estudos brasileiros. Rio de Janeiro: F. Briguiet \& Cia, 1931. 2a série.

CARVALHO, Ronald. Estudos brasileiros. Rio de Janeiro: F. Briguiet \& Cia, 1931. $3^{\text {a }}$ série.

CARVALHO, Ronald. Macunaíma, de Mário de Andrade. In: ANDRADE, Mário de. Macunaíma: o herói sem nenhum caráter. Ed. crítica de Telê Porto Ancona Lopez. Rio de Janeiro: Livros Técnicos e Científicos, 1978. p. 352.

CASCUDO, Câmara. Literatura oral no Brasil. Belo Horizonte: Editora Itatiaia, 1984.

JOBIM, José Luís. Os estudos literários e a identidade da literatura. In. JOBIM, José Luís (Org.). Literatura e identidades. Rio de Janeiro: Ed. UERJ, 1999.

JOBIM, José Luís. Formas da teoria: sentidos, conceitos, políticas e campos de força nos estudos literários. Rio de Janeiro: Caetés, 2002.

JOBIM, José Luís. Trocas e transferências literárias e culturais: escritores e intelectuais nas Américas. In: JOBIM, José Luís (Org.). Trocas e transferências literárias e culturais: do nacional aos blocos transnacionais. Escritores e intelectuais nas Américas. Niterói/ Rio de Janeiro: EDUFF/De Letras, 2008.

KOCH-GRÜNBERG, Theodor. Mitos e lendas dos índios Taulipang e Arekuná. In: MEDEIROS, Sérgio (Org.). Makunaima e Jurupari. Cosmogonias ameríndias. São Paulo: Perspectiva, 2002.

KOCH-GRÜNBERG, Theodor. Do Roraima ao Orinoco. Observações de uma viagem pelo norte do Brasil e pela Venezuela durante os anos de 1911 a 1913. Trad. Cristina Alberts-Franco. São Paulo: Ed. UNESP, 2006.

LIMA, Jorge de. Macunaíma: um raide no subconsciente nacional. In: ANDRADE, Mário de. Macunaíma; o herói sem nenhum caráter. Ed. crítica de Telê Porto Ancona Lopez. Rio de Janeiro: Livros Técnicos e Científicos, 1978. p. 348-351.

LOPEZ, Telê Porto Ancona. Ramais e caminhos. São Paulo: Duas Cidades, 1972.

LOPEZ, Telê Porto Ancona. Macunaima: a margem e o texto. São Paulo: Hucitec/ Secretaria de Cultura, Esportes e Turismo, 1974.

LOPEZ, Telê Porto Ancona. Introdução. In: ANDRADE, Mário de. Macunaíma, o herói sem nenhum caráter. Ed. crítica de Telê Porto Ancona Lopez. Rio de Janeiro: Livros Técnicos e Científicos, 1978. p. XV-LX.

LOPEZ, Telê Porto Ancona. Uma difícil conjugação. In: ANDRADE, Mário de. Amar, verbo intransitivo. Belo Horizonte: Rio de Janeiro, 1993. 
LOPEZ, Telê Porto Ancona. Revisitando Sísifo. Preparando a possessão. In: ANDRADE, Mário de. Macunaíma. Ed. crítica Telê Porto Ancona Lopez. Madrid: ALLCA XX, 1997. p. XXVII.

LOPEZ, Telê Porto Ancona. O turista aprendiz na Amazônia: a invenção no texto e na imagem. An. Mus. Paul., São Paulo, v. 13, n. 2, dez. 2005.

MACHADO, A. de Alcântara. Mário de Andrade: Macunaíma. In: ANDRADE, Mário de. Macunaima; o herói sem nenhum caráter. Ed. crítica de Telê Porto Ancona Lopez. Rio de Janeiro: Livros Técnicos e Científicos, 1978. p. 340-341.

MEYER, Augusto. Macunaíma, por Mário de Andrade. In: ANDRADE, Mário de. Macunaíma; o herói sem nenhum caráter. Ed. crítica de Telê Porto Ancona Lopez. Rio de Janeiro: Livros Técnicos e Científicos, 1978. p. 347-348.

MORAES, Marcos Antonio de. Mário de Andrade entre a erudição e o conhecimento. In: PROENÇA, M. Cavalcanti. Roteiro de Macunaíma. 5. ed. Rio de Janeiro: Civilização Brasileira, 1978.

RIBEIRO, João. Macunaíma, Herói sem nenhum caráter - por Mário de Andrade. In: ANDRADE, Mário de. Macunaíma; o herói sem nenhum caráter. Ed. crítica de Telê Porto Ancona Lopez. Rio de Janeiro: Livros Técnicos e Científicos, 1978. p. 344-346.

VICTOR, Nestor. Macunaíma. In: ANDRADE, Mário de. Macunaíma: o herói sem nenhum caráter. Ed. crítica de Telê Porto Ancona Lopez. Rio de Janeiro: Livros Técnicos e Científicos, 1978. p. 341-344. 